\title{
UTILIZAÇÃO DE UMA INTERFACE DO TIPO "PARTICLE BEAM" PARA A OBTENÇÃO DE ESPECTROS DE MASSAS DE COMPOSTOS POUCO VOLÁTEIS EM SOLUÇÃO
}

Rodinei Augusti", Adelson de O. Dias e Isabel C. P. Fortes*

Departamento de Química - ICEx - Universidade Federal de Minas Gerais - CP 702 - 31270-901 - Belo Horizonte - MG

Recebido em 11/6/97; aceito em 14/1/98

UTILIZATION OF A PARTICLE BEAM INTERFACE FOR THE OBTAINTION OF MASS SPECTRA OF LOW VOLATILE COMPOUNDS IN SOLUTION. Due to source contamination and wearing of instrument components problems caused by the direct insertion probe technique, a new way of introduction of low volatile compounds into mass spectrometer was tested. This new scheme comprises the introduction of the low volatile compounds solutions via a six port valve connected to a particle beam interface. Solutions of isatin were injected into this system and the best results were obtained with $\mathrm{CH}_{2} \mathrm{Cl}_{2}, \mathrm{CH}_{3} \mathrm{OH}$ and $\mathrm{CH}_{3} \mathrm{CN}$. The solution inlet system has shown to be advantageous over the conventional way of direct insertion probe introduction.

Keywords: mass spectrometry; particle beam interface; low volatile compounds.

\section{INTRODUÇ̃̃̃O}

Existem várias maneiras de se introduzir amostras no espectrômetro de massas dependendo de sua volatilidade e termoestabilidade. Amostras que apresentam alta volatilidade e termoestabilidade, podem ser introduzidas via cromatografia gasosa (GC), enquanto aquelas que possuem volatilidade menor podem ser introduzidas via cromatografia líquida (LC). Nestes casos, as amostras são usualmente constituídas por mais de um componente. Há ainda uma outra técnica, denominada inserção direta, onde a amostra pura, líquida ou sólida, é introduzida diretamente no espectrômetro de massas (MS) através de uma sonda. Esta técnica, porém, apresenta algumas limitações, tais como a decomposição térmica de algumas amostras e a maior contaminação do aparelho. Esta última é bastante marcante, principalmente no caso de amostras sólidas. Assim, mesmo utilizando-se pequenas quantidades de amostra $(0,5$ a $1 \mathrm{mg})$ há uma contaminação muito rápida do sistema, gerando um desgaste maior dos componentes do aparelho, principalmente filamento e multiplicador de elétrons. Consequentemente, há a necessidade de uma limpeza mais freqüente da fonte de íons, o que se torna um procedimento inconveniente ${ }^{1}$.

Com o intuito de se minimizar ao máximo os problemas acima descritos foram feitas algumas adaptações na técnica de inserção direta utilizando-se, para tanto, uma interface do tipo "particle beam". Esta interface é uma das muitas utilizadas entre espectrômetros de massas e cromatográfos a líquido e permite que o volume em excesso de material proveniente desses cromatógrafos seja removido e, consequentemente, o alto vácuo requerido no espectrômetro de massas seja mantido. $\mathrm{O}$ processo de separação amostra/ solvente é realizado pela interface da seguinte maneira:

- convertendo o eluente do cromatógrafo líquido em um aerosol

- vaporizando a fase líquida móvel mais volátil

- separando as partículas da amostra da fase móvel

- transportando as partículas da amostra à fonte de íons do espectrômetro de massas

Cada um desses passos é ilustrado na figura 1.

\section{EXPERIMENTAL}

Para a realização dos experimentos, utilizou-se um espectrômetro de massas HP 5989A série II, uma interface particle

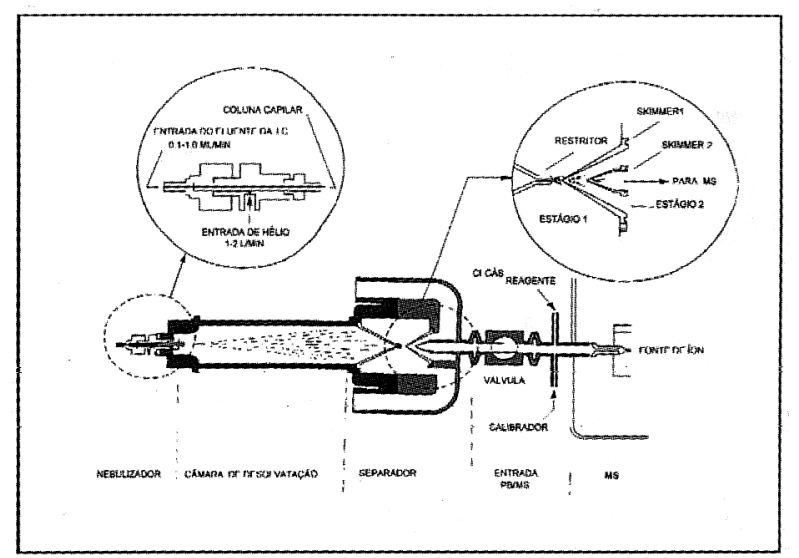

Figura 1. Representação do modo de ação de uma interface particle beam. Adaptado da referência 2.

beam HP 59980B, uma válvula Rheodyne de seis entradas com injetor e uma bomba peristáltica Intralab. Os espectros de massas foram obtidos através do modo de impacto de elétrons a $70 \mathrm{eV}$, segundo montagem descrita no Esquema 1. No interior da primeira sessão da interface foi mantida uma pressão constante de 40 torr, através de um fluxo contínuo de gás hélio,

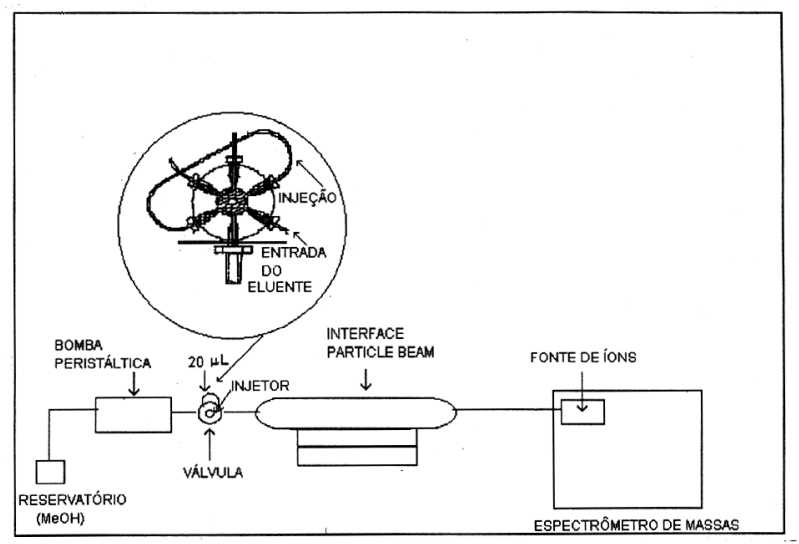

Esquema 1. 
com o objetivo de converter a vazão de líquidos que adentra à interface num aerossol adequado (Figura 1). Bombeou-se continuamente, através da bomba peristáltica, uma vazão de 0,5 $\mathrm{mL} / \mathrm{min}$ de metanol para o sistema.

Foram preparadas soluções de isatina, com concentrações em torno de $500 \mathrm{ppm}$, utilizando diclorometano, metanol, acetonitrila ou dimetilsulfóxido como solvente ${ }^{3}$. Um volume aproximado de $50 \mu \mathrm{L}$ de cada uma destas soluções foi injetado pela abertura na válvula, que continha um looping de $20 \mu \mathrm{L}$, permitindo que apenas este volume de cada uma das soluções adentrasse à interface. Os espectros de massas foram obtidos continuamente.

\section{RESULTADOS E DISCUSSÃO}

Visando testar a viabilidade da obtenção de espectros de massas de compostos pouco voláteis em solução através da utilização da montagem descrita no esquema 1 , foram feitas injeções consecutivas das quatro soluções mencionadas anteriormente, e os resultados são apresentados na figura 2. A partir desses resultados, foi verificado que os solventes mais adequados para a preparação das soluções devem atender a pelo menos uma das seguintes condições:

a) possuir baixo ponto de ebulição (menor que $50^{\circ} \mathrm{C}$ ) pois, neste caso, são facilmente eliminados na interface.

b) possuir baixo peso molecular (menor que $50 \mathrm{u}$.). A exclusão dos íons com relação massa/ carga $(\mathrm{m} / \mathrm{z})$ menores que 50 (eliminação das interferências do solvente) não provoca perdas significativas de informações no espectro de massas da isatina

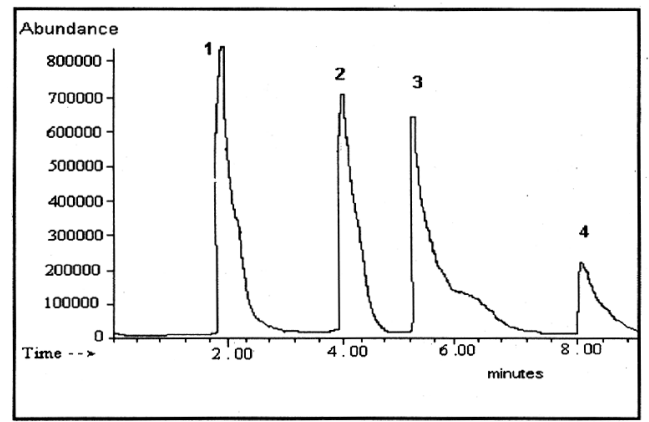

Figura 2. Resultados das injeções consecutivas das soluções de isatina. Os números acima dos picos referem-se aos solventes utilizados na preparação destas soluções: diclorometano (1), metanol (2), acetonitrila (3) e dimetil sulfóxido (4).

Dentre os solventes que foram utilizados na preparação das soluções, aqueles que apresentaram os melhores resultados foram acetonitrila, diclorometano e metanol. Observou-se que a utilização desses solventes, que atendem a pelo menos uma das condições mencionadas anteriormente, não afeta o espectro de massas da isatina, já que nenhum pico proveniente desses solventes é detectado, como pode ser visto na figura 3 . Vale ainda ressaltar que nestes três casos, o espectro de massas da isatina apresentou grande semelhança (maior que 90\%) com o espectro encontrado na biblioteca disponível no equipamento (Wiley138). Porém, a utilização do dimetil sulfóxido como solvente, que possui um alto ponto de ebulição $\left(189^{\circ} \mathrm{C}\right)$ e um peso molecular $(78 \mathrm{u})$ maior que $50 \mathrm{u}$, não é aconselhável pois,

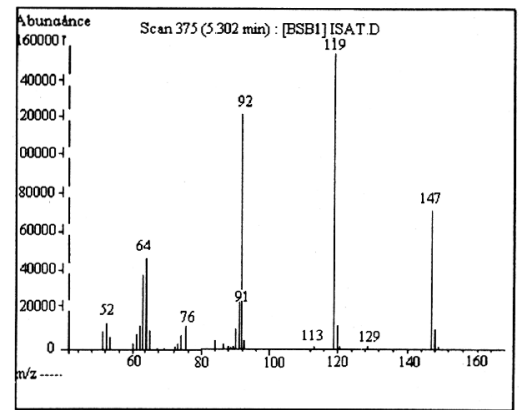

Figura 3. Espectro de massas da isatina obtido por inserção via interface "particle beam" a partir da solução de diclorometano. Os espectros obtidos a partir das soluções de metanol e acetonitrila mostraram-se idênticos a esse.

no respectivo espectro de massas, detectou-se os picos provenientes de sua ionização e fragmentação $(\mathrm{m} / \mathrm{z} 78$ e 63$) \mathrm{com}$ intensidade não desprezível e isto, em trabalhos onde a identificação da estrutura é imprescindível, pode levar à interpretações equivocadas.

\section{CONCLUSÕES}

Verificou-se que a introdução de amostras via uma interface "particle beam" apresenta vantagens em comparação ao modo convencional de inserção direta, ou seja, a rapidez da análise (pode-se realizar várias análises num curto espaço de tempo) e a redução do desgaste de alguns componentes do equipamento, especialmente o filamento e o multiplicador de elétrons, permitindo que a fonte de íons permaneça um maior tempo em condições operacionais. Além disso, a interface "particle beam" pode ser facilmente colocada e removida para dar lugar a uma sonda de sólidos, não precisa ser limpa periodicamente e, quando este é o caso, a limpeza é um procedimento extremamente simples. Finalmente, o sistema pode ser utilizado na obtenção de espectros de massas de substâncias instáveis ao ar, mas estáveis em solução ${ }^{4}$. Com relação às desvantagens do método, as mesmas estão relacionadas ao elevado consumo de hélio $(2 \mathrm{~L} / \mathrm{min})$ pela interface e à impossibilidade de obtenção de espectros de massas de amostras insolúveis nos solventes usuais. Neste caso, a única alternativa seria a obtenção dos respectivos espectros de massas através do modo de inserção direta.

\section{AGRADECIMENTOS}

Agradecemos à técnica do laboratório de cromatografia, Vany Perpétua Ferraz, por gentilmente ter-nos cedido a bomba peristáltica e a válvula de seis entradas. AOD agradece ao CNPq pela bolsa de IC concedida.

\section{REFERÊNCIAS E NOTAS}

1. Chapman, J. R.; Practical Organic Mass Spectrometry; John Wiley \& Sons Ltd; Chichester, England, 1994; p. 43.

2. Manual de operações do espectrômetro de massas HP5989A, Volume 2, pg. A11.

3. As soluções foram preparadas a partir de reagentes analíticos Merck ou Aldrich.

4. Esta última aplicação não foi demonstrada neste trabalho. 